\title{
ARTIGOS
}

\section{COTIDIANO ESCOLAR E PRÁTICAS INTERCULTURAIS}

VERA MARIA FERRÃO CANDAU

\section{RESUMO}

$\mathrm{Na}$ sociedade brasileira existe uma crescente sensibilidade para a temática das diferenças culturais que se manifesta em diversos âmbitos sociais. No entanto, no que se refere à educação escolar, é possível detectar uma sensação de impotência, de não sabermos como lidar positivamente com essas questões. É nesse universo de preocupações que se situa o presente trabalho. Seu objetivo é analisar as relações entre escola e práticas interculturais, tendo como referência um curso inspirado na pesquisa-ação, desenvolvido no primeiro semestre de 2014, visando à incorporação da perspectiva intercultural no cotidiano escolar. Concluímos que, para avançar nessa perspectiva, é importante que ela seja introduzida nos processos de formação continuada realizados coletivamente na própria escola.

COTIDIANO ESCOLAR • PRÁTICAS INTERCULTURAIS • PESQUISA-AÇÃO

\section{SCHOOL ROUTINE AND INTERCULTURAL PRACTICES}

\section{ABSTRACT}

In Brazilian society there is an increasing concern about cultural differences in various social contexts. However, in regards to school education, it is possible to notice the feeling of not knowing how to deal with these issues in a positive way. This study aims at analyzing the relationship between school and intercultural practices. A course that was inspired in an action research that took place in the first semester of the year 2014 was used as reference. The goal of this course was to incorporate the intercultural perspective in the school routine. As a result, we found that to advance on this matter, it is important to bring the intercultural perspective into our ongoing training within the school space and routine. 


\section{QUOTIDIEN SCOLAIRE ET PRATIQUES INTERCULTURELLES \\ RÉSUMÉ}

Dans la société brésilienne, il y a souci croissant concernant la thématique des différences culturelles qui se manifeste dans divers domaines sociaux. Cependant, en ce qui se rapporte à l'éducation scolaire, il est possible d'observer un sentiment d'impuissance, d'incapacité de gérer positivement ces sujets. C'est autour de ces questionnements que s'organise le présent travail. Son objectif est d'analyser les rapports entre l'école et les pratiques interculturelles. La référence est un cours, qui s'est déroulé pendant le premier semestre de 2014, inspiré de la rechercheaction et ayant comme but l'intégration de la perspective interculturelle dans le quotidien scolaire. Nous avons conclu qu'afin d'avancer dans cette perspective il est important de l'intégrer dans les processus de formation continue développés collectivement dans l'école même.

QUOTIDIEN SCOLAIRE • PRATIQUES INTERCULTURELLES • RECHERCHE-ACTION

\section{COTIDIANO ESCOLAR Y PRÁCTICAS INTERCULTURALES RESUMEN}

En la sociedad brasileña hay una creciente sensibilidad para la temática de las diferencias culturales que se manifiesta en diversos ámbitos sociales. Sin embargo, en relación con la educación escolar es posible identificar una sensación de impotencia, de no saber cómo trabajar positivamente con estas cuestiones. El presente trabajo se sitúa en este universo de preocupaciones. Su objetivo es analizar las relaciones entre la escuela y las prácticas interculturales, a partir de un curso inspirado en la investigación-acción, desarrollado en el primer semestre de 2014, teniendo como eje la incorporación de la perspectiva intercultural en el cotidiano escolar. Una de las conclusiones del estudio fue que, para avanzar en esta perspectiva, es importante introducirla en los procesos de formación continuada promovidos en la propia escuela con carácter colectivo. 


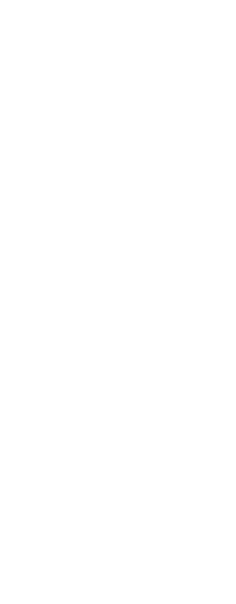

elações ÉtNico-racials, questões de gênero e sexualidade, PLURALISMO religioso, relações geracionais, culturas infantis e juvenis, povos tradicionais e educação diferenciada, entre outros, são temas fortemente presentes na sociedade brasileira na atualidade. Tais assuntos provocam debates, controvérsias e reações de intolerância e discriminação, assim como suscitam diversas iniciativas orientadas a trabalhá-las numa perspectiva direcionada à afirmação democrática, ao respeito à diferença e à construção de uma sociedade em que todos e todas possam ser plenamente cidadãos e cidadãs.

Existe, sem dúvida, uma crescente sensibilidade para essa temática, que se manifesta em diversos âmbitos sociais: dos partidos políticos aos movimentos sociais; das ruas às redes sociais; das manifestações artísticas à produção acadêmica. Políticas públicas são construídas e orientadas à promoção dos direitos dos diversos grupos socioculturais discriminados e subalternizados. Articular políticas de igualdade e políticas de identidades tem sido uma preocupação fundamental tanto de instâncias governamentais quanto de movimentos sociais, organizações não governamentais e outros atores da sociedade civil.

No entanto, no âmbito da educação escolar, é possível detectar uma sensação de impotência, de não sabermos como lidar positivamente com essas questões. Em pesquisa realizada anteriormente (CANDAU, 
2008b), um professor entrevistado afirmou: "as diferenças estão bombando na escola e não sabemos o que fazer”. As diferenças culturais são muitas vezes vistas como problemas que a escola deve resolver. Estamos longe de encará-las como vantagem pedagógica, como nos propõe a educadora argentina Emilia Ferreiro ${ }^{1}$ (apud LERNER, 2007).

É nesse universo de preocupações que se situa o presente trabalho, elaborado no contexto da pesquisa "Direitos Humanos, Educação, Interculturalidade: construindo práticas pedagógicas”, que está sendo desenvolvida desde 2012, com o apoio do Conselho Nacional de Desenvolvimento Científico e Tecnológico - CNPq -, por meio do Grupo de Estudos sobre Cotidiano, Educação e Culturas - Gecec -, vinculado ao Programa de Pós-graduação em Educação da Pontifícia Universidade Católica do Rio de Janeiro - PUC-Rio. Seu objetivo principal é analisar as relações entre escola e práticas interculturais, tendo como referência um curso inspirado na pesquisa-ação, que desenvolvemos no primeiro semestre de 2014, visando à incorporação da perspectiva da interculturalidade no cotidiano escolar. ${ }^{2}$

O texto está estruturado em quatro seções. A primeira aborda sinteticamente como vemos a problemática da educação escolar hoje. Em seguida, é discutida a concepção de educação intercultural em que nos baseamos, bem como nossa posição em relação ao potencial provocador da pesquisa-ação para a transformação das práticas educativas. Apresentamos a experiência desenvolvida e terminamos tecendo algumas considerações sobre as possibilidades e limites da incorporação da perspectiva intercultural nas nossas escolas na atualidade.

\section{ESCOLA HOJE: CONTEXTO E DESAFIOS}

Muitas das políticas educacionais hoje vigentes nos países latino-americanos orientadas à educação escolar enfatizam dois aspectos fundamentais: a avaliação e a gestão. Multiplicaram-se as avaliações em larga escala, os testes nacionais e internacionais que pretendem medir o desempenho dos alunos em determinadas áreas curriculares. Essa lógica vem se afirmando cada vez com maior força, a ponto de construir uma verdadeira "cultura da avaliação”, que termina por orientar os processos de ensino-aprendizagem das escolas de ensino básico, segundo depoimentos de inúmeros educadores/as.

Para garantir esse processo, investe-se na gestão dos sistemas de ensino, partindo-se do pressuposto de que ela permite o controle e o monitoramento do processo como um todo, identificando seus pontos débeis e investindo-se na operacionalização e na produtividade do sistema. Formas próprias do modelo de gestão do setor corporativo são aplicadas diretamente à educação, sem serem consideradas as especificidades desse âmbito, entendendo-se implicitamente que são adequadas em qualquer âmbito de "produção".

1

FERREIRO, E. Diversidad y proceso de alfabetización. De la celebración a la toma de conciencia. En: FERREIRO, E. Pasado y presente de los verbos leer y escribir. Buenos Aires: Fondo de Cultura Económico, 2001. 2 Agradecemos a participação de Adélia Maria Nehme e Koff e de Maria Elisa Almeida Bacal, membros do Gecec, no desenvolvimento da experiência, assim como suas sugestões para o enriquecimento do presente texto. 
Essa lógica não é uma novidade e tem sido utilizada em muitos países; no entanto, vem sendo fortemente contestada. Foram amplamente divulgadas as afirmações de Diane Ravitch (2011), autora norte-americana com ampla experiência acadêmica e atuação na formulação de políticas públicas em educação nos Estados Unidos. Depois de 20 anos de envolvimento e apoio a essas políticas orientadas pelos princípios do mercado e da competição, ela faz uma corajosa autocrítica e afirma que os seus efeitos não foram positivos, o ensino não melhorou e os sistemas de premiação aos professores pelos resultados dos alunos nos testes terminaram por estimular formas de burlar os resultados, procurando-se ensinar aos alunos modos de lidar melhor - "truques" - com os testes padronizados.

Nossa leitura dessa avalanche de testes padronizados e políticas de premiação assume perspectiva semelhante, pois acaba concebendo o processo educacional basicamente como ensino de alguns conhecimentos específicos. Educar fica reduzido a ensinar. Ensinar a instruir. Instruir a preparar para ter êxito em testes padronizados. Esse processo termina reduzindo a educação a questões meramente operacionais.

Nesse contexto, na nossa perspectiva, o pensamento pedagógico tem tido um desenvolvimento que pode ser classificado de fraco, com pouco debate entre os diferentes atores implicados para o aprofundamento em questões que focalizem o sentido da escolarização hoje. As questões instrumentais dos processos educativos centralizam as discussões e políticas públicas. Os temas relativos ao sentido da educação escolar e seu formato historicamente construído não são discutidos, por mais que os desafios enfrentados por escolas e professores/as se multipliquem e apresentem, em episódios emblemáticos, caráter dramático.

Para o sociólogo francês François Dubet (2011, p. 299):

Em todos os lugares e não somente na escola, o programa institucional [republicano] declina. E essa mutação é muito mais ampla que a simples confrontação da escola com novos alunos e com os problemas engendrados por novas demandas. É também porque se trata de uma mutação radical que a identidade dos atores da escola fica fortemente perturbada, para além dos problemas específicos com os quais eles se deparam.

A escola foi um programa institucional moderno, mas um programa institucional apesar de tudo. Hoje somos "ainda mais modernos", as contradições desse programa explodem, não apenas sob o efeito de uma ameaça externa, mas de causas endógenas, inscritas no germe da própria modernidade.

O "formato" escolar predominante continua estruturado a partir dos referentes da modernidade, que são naturalizados e, mesmo, 
terminam por ser essencializados. Parece que há uma única e verdadeira maneira de se pensar a escola, seus espaços e tempos, sua lógica de organização curricular, sua dinâmica e, até mesmo, sua decoração e linguagem visual. Tudo parece concorrer para afirmar a homogeneização e padronização. Acreditamos que somente avançaremos na construção de uma qualidade adequada aos tempos atuais se questionarmos essa lógica. Caso contrário, continuaremos enfatizando medidas paliativas e cosméticas.

É importante ter presente que já existem nos sistemas educativos experiências "insurgentes" que apontam para outros paradigmas escolares: outras formas de organizar os currículos, os espaços e tempos, o trabalho docente, as relações com as famílias e comunidades, de conceber a gestão de modo participativo, enfatizando as práticas coletivas, a partir de um conceito amplo e plural de sala de aula, etc. Mas essas experiências permanecem periféricas, não são adequadamente visibilizadas, nem fortemente apoiadas.

Consideramos fundamental "reinventar a escola" (CANDAU, 2010) para que possa responder aos desafios da sociedade em que vivemos. Não acreditamos na padronização, em currículos únicos e engessados e perspectivas que reduzem o direito à educação a resultados uniformes. Acreditamos no potencial dos educadores para construir propostas educativas coletivas e plurais. É tempo de inovar, atrever-se a realizar experiências pedagógicas a partir de paradigmas educacionais “outros”, mobilizar as comunidades educativas na construção de projetos político-pedagógicos relevantes para cada contexto. Nesse horizonte, a perspectiva intercultural pode oferecer contribuições especialmente relevantes.

\section{O QUE ENTENDEMOS POR EDUCAÇÃO INTERCULTURAL}

Desde 1996 vimos desenvolvendo trabalhos sistemáticos - pesquisas, teses, dissertações, artigos, apresentação de trabalhos em congressos e seminários, etc. - sobre diversos aspectos das relações entre educação e culturas (CANDAU, 1998, 2000, 2002, 2003, 2004, 2005, 2006, 2008a, 2008b, 2009, 2010, 2011, 2012).

Uma reflexão constante sobre o multiculturalismo e a interculturalidade integra esse processo. No presente artigo não se pretende fazer uma síntese do caminho percorrido, mas apenas assinalar a polissemia dos termos multiculturalismo e interculturalidade e mencionar que a educação intercultural apresenta uma trajetória original, plural e especialmente criativa na América Latina.

Na nossa produção, três afirmações foram adquirindo cada vez maior centralidade na perspectiva de se aprofundar na temática da 
interculturalidade nos contextos educativos. A primeira refere-se à relação entre diferenças culturais e direitos humanos. Partimos do ponto de vista de que a relação entre questões sobre justiça, superação das desigualdades e democratização de oportunidades e aquelas que dizem respeito ao reconhecimento de diferentes grupos socioculturais se faz cada vez mais estreita. Já a segunda afirmação tem a ver com a relação entre multiculturalismo e interculturalidade. Assumimos a posição que propõe um multiculturalismo aberto e interativo, que acentua a interculturalidade por considerá-la a mais adequada para a construção de sociedades democráticas, que articulem políticas de igualdade com políticas de identidade. Um terceiro eixo articulador do nosso trabalho tem sido, particularmente no que se refere à educação escolar, a afirmação de que somos chamados a construir novos "formatos" escolares, que respondam aos desafios sociais, culturais e educacionais que enfrentamos hoje.

Entre as diversas concepções de educação intercultural que atravessam a literatura sobre essa temática (WALSH, 2009), assumimos a perspectiva da interculturalidade crítica e sublinhamos algumas de suas características: promove a deliberada inter-relação entre diferentes sujeitos e grupos socioculturais de determinada sociedade; nesse sentido, essa posição se situa em confronto com todas as visões diferencialistas, assim como com as perspectivas assimilacionistas; por outro lado, rompe com uma visão essencialista das culturas e das identidades culturais; concebe as culturas em contínuo processo de construção, desestabilização e reconstrução; está constituída pela afirmação de que nas sociedades em que vivemos os processos de hibridização cultural são intensos e mobilizadores da construção de identidades abertas, o que supõe que as culturas não são puras, nem estáticas; e tem presente os mecanismos de poder que permeiam as relações culturais, assumindo que estas não são relações idílicas, estão construídas na história e, portanto, estão atravessadas por conflitos de poder e marcadas pelo preconceito e discriminação de determinados grupos socioculturais. Uma última característica que gostaríamos de assinalar refere-se ao fato de essa perspectiva não desvincular as questões da diferença e da desigualdade presentes hoje de modo particularmente conflitivo, tanto no plano mundial quanto em diferentes sociedades, entre as quais a brasileira.

Partindo dessa visão da interculturalidade crítica, construímos coletivamente um conceito de educação intercultural que é referência para o presente trabalho: 
assim como da construção de relações igualitárias entre grupos socioculturais e da democratização da sociedade, através de políticas que articulam direitos da igualdade e da diferença. (CANDAU, 2014, p. 1)

Gostaríamos de ressaltar a primeira afirmação, que consideramos central. O termo diferença, em depoimentos de educadores em várias pesquisas que realizamos, é frequentemente associado a um problema a ser resolvido, à deficiência, ao déficit cultural e à desigualdade. Diferentes são aqueles que têm baixo rendimento acadêmico, provêm de comunidades de risco e de famílias com condições de vida de grande vulnerabilidade social e possuem comportamentos que apresentam níveis diversos de violência e incivilidade. Trata-se de pessoas com características identitárias que são associadas à “anormalidade”, a "necessidades especiais” e/ou a um baixo capital cultural. Enfim, os diferentes são um problema que a escola e os/as educadores/as precisam enfrentar e essa situação vem se agravando e não sabemos como lidar com ela. Somente em poucos depoimentos, a diferença é articulada a identidades plurais que enriquecem os processos pedagógicos e devem ser reconhecidas e valorizadas.

No entanto, se não logramos mudar de ótica e situar-nos diante das diferenças culturais como riquezas que ampliam nossas experiências, dilatam nossa sensibilidade e nos convidam a potencializá-las como exigência da construção de um mundo mais igualitário, não poderemos ser atores de processos de educação intercultural na perspectiva que assinalamos. E, para tal, somos chamados a desconstruir aspectos da dinâmica escolar naturalizados que nos impedem de reconhecer positivamente as diferenças culturais e, ao mesmo tempo, promover processos que potencializem essa perspectiva. Foi nessa direção que pretendemos caminhar a partir da experiência que desenvolvemos, inspirada na pesquisa-ação.

\section{A PESQUISA-AÇÃO: UMA REFERÊNCIA PROVOCADORA}

É importante salientar que são utilizadas diferentes expressões, tais como pesquisa-ação, pesquisa colaborativa, pesquisa participante, pesquisa intervenção, etc., que, com diversas nuances, referem-se à possibilidade de associar, num processo de investigação, a produção de conhecimento e a intervenção na realidade. Essa abordagem é especialmente relevante quando a preocupação com processos de mudança está no horizonte da investigação, mas, nesse tipo de pesquisa, também encontra-se muito presente o risco de se dar centralidade à intervenção e minimizar a produção de conhecimento. Acreditamos que essa tensão 
realmente atravessa as pesquisas dessa natureza, mas consideramos que elas são especialmente adequadas sempre que a construção de novas práticas constitui um dos objetivos propostos, como é o nosso caso.

Para Gatti (2008, p. 8), essas pesquisas, em suas diversas modalidades e expressões,

\begin{abstract}
[...] propiciaram a construção de uma nova direção na busca da compreensão de fatos, situações, ações humano-sociais e educacionais em sua especificidade, sobretudo nas questões escolares. Ao mesmo tempo em que se integram organisticamente com as ações pedagógicas, propiciam ricos processos "homeostáticos", de trocas enriquecedoras, flexíveis, ajustáveis, em e para situações educativas.
\end{abstract}

Uma das áreas em que a pesquisa-ação tem sido mais utilizada é exatamente quando o foco são as práticas educativas e especialmente no âmbito da sala de aula. Também é considerada um componente muito relevante para o desenvolvimento profissional dos educadores e agentes sociais.

Neste trabalho teremos como referência a concepção de Michel Thiollent (2011, p. 14), apresentada no livro Metodologia da pesquisa-ação.

\footnotetext{
Entre as diversas definições possíveis, daremos a seguinte: a pesquisa-ação é um tipo de pesquisa social com base empírica que é concebida e realizada em estreita associação com uma ação ou com a resolução de um problema coletivo e no qual os pesquisadores e os participantes representativos da situação ou do problema estão envolvidos de modo cooperativo ou participativo.
}

Utilizamos a inspiração da pesquisa-ação no curso que desenvolvemos, trabalhando com os professores envolvidos na articulação teoria-prática, como será descrito a seguir. A palavra “inspiração” é proposital e consciente. Devido aos limites da experiência desenvolvida - sua especificidade e o tempo disponível -, consideramos que foi dado um primeiro passo tendo como referência o potencial da pesquisa-ação.

\title{
CONSTRUINDO PRÁTICAS EDUCATIVAS INTERCULTURAIS: UMA EXPERIÊNCIA
}

No primeiro semestre de 2014, desenvolvemos uma disciplina intitulada "Educação Intercultural e Práticas Pedagógicas", oferecida aos alunos e alunas do Programa de Pós-Graduação em Educação da PUC-Rio. A referida disciplina, de caráter eletivo, exigia como condição de matrícula que os participantes estivessem em exercício docente na escola básica e sua metodologia teve como inspiração a pesquisa-ação. Realizamos, de fevereiro 
a junho, encontros semanais de três horas cada. Em geral, esses encontros foram gravados em áudio e feita a transcrição de cada um deles.

Um dos desafios enfrentados foi o de continuamente ajustar a dinâmica do curso devido aos feriados motivados pela realização dos jogos do Brasil na Copa Mundial ou de outros jogos na cidade, assim como em função das mobilizações sociais que se multiplicaram, especialmente na segunda quinzena do mês de maio. Apesar dessas circunstâncias, a disciplina atendeu aos requisitos fundamentais propostos.

No primeiro encontro, realizado em 27 de fevereiro, além da apresentação dos integrantes do grupo e de suas expectativas em relação ao curso, foi exposta a proposta do mesmo, discutida como seria incorporada a perspectiva da pesquisa-ação e foram construídas conjuntamente as questões que norteariam os trabalhos.

As integrantes - todas professoras - constituíram um grupo pequeno e heterogêneo, formado por pessoas com diferentes formações acadêmicas - biologia, educação física, música, letras-inglês e matemática -, todas vinculadas a redes públicas de ensino municipal (Rio de Janeiro e Petrópolis), estadual (Rio de Janeiro) e a um dos colégios de aplicação de universidades situadas na cidade do Rio de Janeiro, cursando a pós-graduação em educação, em nível de mestrado ou doutorado, em diferentes universidades, PUC-Rio, Universidade Federal do Rio de Janeiro - UFRJ - e Universidade Federal Fluminense - UFF. Também integraram o grupo duas professoras pesquisadoras, membros do Gecec. Uma delas registrou em seu caderno de campo: "percebemos que o que une o grupo é uma inquietude/preocupação em como construir um currículo com olhar multicultural e de que maneira concretizar a interculturalidade no currículo e no cotidiano escolar" (Ana). ${ }^{3}$

Todas as participantes receberam um caderno de campo, onde deveriam registrar de modo sistemático suas observações, experiências, impressões e comentários, e um CD-ROM com os principais textos que serviriam de base para o curso, agrupados em cinco eixos: conceito de cultura; cultura escolar; relações entre igualdade e diferença; educação multi/intercultural; e práticas educativas interculturais. Também, nesse primeiro encontro, todas assinaram um Termo de Consentimento Livre e Esclarecido, orientado à sua participação na pesquisa e à autorização para utilização dos dados construídos em produções acadêmicas.

Convergimos no fato de que o nosso foco seria se aprofundar no processo de interculturalizar a escola, o currículo e a sala de aula. Foram definidas como questões orientadoras do curso as seguintes:

De que maneira a Interculturalidade pode se concretizar e/ou pode acontecer impactando o currículo e a prática pedagógica no coti- 3 diano da sala de aula? 
Quais as dificuldades para que isso aconteça? Quais os elementos potencializadores?

Como desestabilizar a questão da monoculturalidade que configura a escola e que afeta a própria visão que temos dos/as alunos/as e dos conhecimentos/saberes?

A metodologia utilizada no curso supôs a realização de diferentes exercícios orientados a trabalhar o "olhar" e a sensibilidade em relação a diversas dimensões do cotidiano escolar em que as diferenças culturais podem ou não se manifestar, interagir com os colegas sobre essas questões, elaborar planejamentos de práticas educativas interculturais, desenvolvê-las e analisá-las, entre outros. Juntamente com as tarefas semanais, textos indicados foram sendo explorados e discutidos, procurando-se privilegiar suas contribuições para ampliar as questões suscitadas.

O primeiro exercício esteve orientado a realizar um texto livre sobre "minha identidade cultural". Temos proposto essa atividade em muitos cursos sobre relações entre educação e culturas que desenvolvemos nos últimos anos. Tem sido recorrente a dificuldade dos professores e professoras em realizarem essa reflexão. Muitos afirmam ser a primeira vez que pensam sobre esse tema e outros limitam-se a um relato descritivo de sua trajetória. Mais uma vez constatamos essa realidade. Não foi fácil para as professoras reconhecerem seu processo de construção identitária do ponto de vista cultural. A tendência é enfatizar características de personalidade. No entanto, consideramos ser esse um ponto de partida fundamental, pois, à medida que tivermos maior capacidade de reconhecer nossas próprias identificações culturais, estaremos também mais abertos e sensíveis aos processos de construção identitária dos demais, nossos alunos e alunas, nossos colegas e amigos.

Convém aqui fazer uma observação: consideramos as identidades processos dinâmicos, históricos, em contínuo movimento. Assumimos o ponto de vista de Boaventura Sousa Santos (1993, p. 31) quando afirma:

\footnotetext{
Mesmo as identidades aparentemente mais sólidas [...] escondem negociações de sentido, jogos de polissemia, choques de temporalidades em constante processo de transformação, responsáveis em última instância pela sucessão de configurações hermenêuticas que de época para época dão corpo e vida a tais identidades. Identidades são, pois, identificações em curso.
}

Foram muitos os exercícios realizados, tais como: promover atividades para conhecer melhor o mundo cultural de nossos alunos/as; identificar elementos importantes, "marcas", da cultura escolar da instituição onde trabalha; observar os painéis da escola - quem organiza, com que frequência são mudados? Que temas e informações são privilegiados? 
Os alunos participam ou não da organização desses painéis? -; escolher um livro didático utilizado na escola e analisá-lo, procurando ver se a diversidade permeia o livro ou não - como são as imagens? O conhecimento é apresentado de modo linear e único? Abre para a possibilidade de outras leituras e conhecimentos? -; construir uma prática pedagógica de caráter intercultural, executá-la e fazer uma apreciação; "conversar” com colegas sobre a diversidade cultural presente na escola; discutir com colegas determinadas frases, como, por exemplo, "a sociedade brasileira é multicultural mas a educação escolar não”, “as práticas multiculturais afirmam as diferenças e terminam por reforçar os conflitos na sociedade e nas escolas"; analisar prática intercultural apresentada por professora externa ao grupo; etc.

A última tarefa do curso foi fazer um trabalho sobre o tema "Interculturalizando minha prática pedagógica: um caminho em construção”.

Muitas foram as constatações, descobertas e desafios que emergiram durante o curso. Vamos destacar alguns deles, tendo presente as questões norteadoras do mesmo.

Um primeiro aspecto que gostaríamos de mencionar é que, apesar de as professoras envolvidas estarem motivadas e interessadas, incorporar a perspectiva intercultural em suas práticas se revelou uma tarefa nada simples.

Acredito que ainda estamos engatinhando nesse assunto; que ain-
da não está claro como implementar em nossas práticas cotidia-
nas, afirmou uma delas e outra: senti uma imensa dificuldade em
pensar uma atividade que não fosse óbvia nem superficial demais,
que promovesse a interculturalidade, articulada com os conteúdos
da minha disciplina. (Ana)

Essa dificuldade está, segundo as participantes, determinada por diferentes aspectos. Sem dúvida, a lógica das políticas públicas dominantes não favorece essa perspectiva. Os docentes se sentem continuamente pressionados pelos múltiplos mecanismos burocráticos, pelas condições de trabalho, pelas inúmeras avaliações locais e nacionais e pela necessidade de garantir desempenhos que permitam às escolas e aos sistemas de ensino obter cada vez mais resultados considerados melhores. Uma professora afirmou: 
Tudo parece favorecer a homogeneidade, a padronização e a monoculturalidade. Talvez, afirma uma professora,

A grande questão seja como desestabilizar a monoculturalidade que configura a escola e que afeta a todos nós, independente dos saberes e conhecimentos com os quais lidamos, esta talvez seja o maior desafio de todos. Ela implica em ir além das práticas individuais e abrange também as políticas públicas, a administração regional (o Estado) e local (a escola), as hierarquias e assimetrias de poder dentro da máquina escolar. (Júlia)

E, nesse contexto, as culturas escolares parecem estar fortemente engessadas. As professoras participantes do curso atuavam em escolas muito diferentes, da educação infantil ao ensino médio, em diversas áreas curriculares. No entanto, por meio dos exercícios realizados, foi possível detectar as principais "marcas" comuns das culturas escolares analisadas: organização padronizada do espaço e dos tempos; ritos formais de avaliação; cultura da avaliação (mais forte nos últimos anos com a multiplicação de provas locais e nacionais, afirmou uma das professoras); ritos de entrada, saída, chamada, uniforme; normatização, disciplinamento, controle; "ordem" escolar e social; adequação às normas hegemônicas e monoculturais do certo, correto, aceitável e bom; sala de aula, em geral com a mesma disposição (alunos enfileirados, quadro negro/verde/branco na frente, etc.); seriação-hierarquização das disciplinas curriculares; em geral painéis a serviço da organização e da gestão da escola; pouca participação dos alunos na construção dos painéis e na decoração da escola. Essa participação se revelou maior nos primeiros anos de escolarização e, em uma única escola, apareceu um painel referido ao sindicato docente e ao grêmio estudantil. Essa escola era o colégio de aplicação de uma universidade pública.

Os exercícios propostos visavam a perceber a cultura escolar pelo ângulo dos símbolos e representações que ela privilegia, identificando as referências culturais que são focalizadas. Por exemplo, como você simboliza a Páscoa numa escola pública? Em geral, repete-se de uma maneira estereotipada o que predomina na sociedade, "tem que ser coelhinho, ovinho", afirmou uma professora, reforçando, assim, determinadas visões. Como a gente pode interculturalizar, isso é, fazer mais diversos, mais plurais, por exemplo, os painéis e os quadros? Uma possibilidade é partir de uma conversa. Permitir a expressão das diferentes vivências, em que apareça a pluralidade. Todos já temos enraizada uma representação, em geral a que é apresentada pela televisão, no comércio. Para 
você desconstruir e pensar de uma maneira mais plural, é importante não partir do espontâneo. O espontâneo vai tender ao que é padronizado. É necessário problematizar, ampliar o “olhar” sobre a temática.

Outro aspecto que consideramos importante ressaltar diz respeito aos livros didáticos analisados. Foram diferentes materiais, desde apostilas produzidas por uma secretaria municipal até livros distribuídos pelo Ministério da Educação para a seleção dos professores. Tendo presente essa diversidade, é possível afirmar que, em geral, os livros estão referidos e têm o foco no conhecimento socialmente reconhecido e valorizado. No entanto, identificamos esforços no sentido de introduzir imagens plurais de diferentes grupos, socioculturais e suas expressões e saberes, em alguns casos fazendo uma apresentação histórica da evolução do conhecimento, assim como elementos orientados a problematizar questões sobre corporeidade, saúde, gênero, relações raciais, etc. Há avanços nessas perspectivas hoje em dia, principalmente se os livros estão selecionados pelo Ministério da Educação, que tem uma série de critérios que devem ser obedecidos e comissões de especialistas que analisam os livros apresentados pelas editoras. A conjugação desses fatores faz com que os livros mais atuais de alguma forma incorporem a temática da diversidade.

Também apareceu com muita força nos depoimentos das professoras a importância do compromisso pessoal do/a educador/a:

Para que possa haver de fato um diálogo, primeiro se faz necessá-
rio que se tenha passado por um momento de "provocação" pes-
soal, movido por uma inquietação, um desconforto. Acredito que
a interculturalidade necessite de algo mais contundente do que o
plano discursivo, de trocas de opiniões e posicionamentos, peda-
gógicos ou políticos. [...] muitas vezes não basta apenas a teoria
para que ocorra uma sensibilização para uma prática intercultural,
as trocas através do diálogo só são de fato trocas quando há uma
predisposição para a abertura a novas perspectivas, novos olhares
e novas formas de fazer. (Lúcia)

Deve-se tentar quebrar as suas próprias resistências e o medo de buscar sensibilizar a escola e as famílias; tem de nascer "dentro de nós”, a partir de predisposições, ideias e convicções que já orientam nossas posturas e formas de ver o mundo. (Júlia)

Consideramos esse um aspecto fundamental. Para o desenvolvimento de uma educação intercultural, é necessário trabalhar o próprio “olhar” do/a educador/a para as questões suscitadas pelas diferenças culturais, como as encara, questionar seus próprios limites e preconceitos e provocar uma mudança de postura. Somente assim ele/a será capaz de 
desenvolver também outro "olhar" para o cotidiano escolar. Foi o que tentamos fazer no curso. E, nesse sentido, um passo que consideramos básico é favorecer a superação do “daltonismo cultural” para podermos promover uma educação intercultural. Essa é uma expressão utilizada pelos conhecidos autores portugueses Stephen Stoer e Luiza Cortesão (1999, p. 56) que assim a justificam:

\begin{abstract}
Ao apontar o multiculturalismo como uma nova forma de globalização, Boaventura Sousa Santos afirma que o mundo é um "arco-íris de culturas" (Santos, 1995). Ora, partindo deste conceito para uma (eventualmente arriscada) analogia, e admitindo que é importante ser capaz de 'ver' este e outros conjuntos de cores, poderemos recordar que algumas pessoas, apesar de disporem de um aparelho visual morfologicamente bem constituído, não são capazes de discernir toda uma gama de tonalidades que compõem o arco-íris. Alguns ficam com uma capacidade reduzida de identificação de tons cinzentos: são os daltônicos. A analogia proposta aqui é a de que a não conscientização da diversidade cultural que nos rodeia em múltiplas situações, constituiria uma espécie de "daltonismo cultural".
\end{abstract}

Essa analogia está orientada a salientar a importância de se desvelar os processos de construção desse "daltonismo cultural”, que favorece o caráter monocultural da cultura escolar e que tem implicações para a prática educativa. Algumas dessas implicações para os/as alunos/as, principalmente aqueles/as oriundos de contextos culturais habitualmente não valorizados pela sociedade e pela escola, são provocadas pela excessiva distância entre suas experiências socioculturais e a escola, favorecendo o desenvolvimento de uma baixa autoestima, elevados índices de fracasso escolar e multiplicação de manifestações de desconforto, mal-estar e agressividade em relação à escola.

O “daltonismo cultural” tende a não reconhecer as diferenças étnicas, de gênero e sexualidade de diversas origens regionais e comunitárias, ou a não colocá-las em evidência na sala de aula por diferentes razões, tais como a dificuldade e falta de preparação para lidar com essas questões, o considerar que a maneira mais adequada de agir é centrar-se no grupo "padrão”, ou, em outros casos, quando se convive com a multiculturalidade quotidianamente em diversos âmbitos, tender a naturalizá-la, o que leva a silenciá-la e não considerá-la um desafio para a prática educativa. Trata-se de um "dado" que não incide na dinâmica promovida pela escola.

Ter presente o "arco-íris das culturas" nas práticas educativas supõe todo um processo de desconstrução de práticas naturalizadas e enraizadas no trabalho docente para sermos educadores/as capazes de 
criar novas maneiras de situar-nos e intervir no dia a dia de nossas escolas e salas de aula.

Sem essa mudança de ótica, a interculturalidade fica reduzida a práticas pontuais e superficiais, como expressa o depoimento de uma das professoras com as quais uma participante do curso conversou: "se a diversidade estiver ligada ao folclore, a escola tentará explorá-la através de projetos, que para ela virou uma moda. Se for ameaçador, vai ignorá-la” (Lúcia).

Podem ser destacados dois aspectos dessa fala. O primeiro é a tendência a reduzir as diferenças culturais a certas expressões, em que o que se faz é introduzir em determinados momentos, em geral eventos de caráter comemorativo, danças, músicas, comidas, de diversos grupos socioculturais considerados diferentes, sem maior preocupação de contextualização, problematização ou desnaturalização. A segunda é a possibilidade de as diferenças culturais terem um caráter ameaçador. Podemos perguntar-nos, em que sentido? Certamente, na perspectiva que adotamos, as diferenças culturais visibilizadas, historicizadas, desnaturalizadas são chamadas a desestabilizar as culturas escolares dominantes, os saberes considerados únicos e verdadeiros para as escolas e as práticas pedagógicas padronizadas, apontando para a sua diversificação e para utilização de diversas linguagens. Se aprofundarmos nas questões suscitadas pelas diferenças culturais no cotidiano escolar, múltiplas dimensões das culturas escolares dominantes serão problematizadas, desconstruídas e chamadas a serem reinventadas.

Entre as propostas das participantes consideradas elementos potencializadores da educação intercultural, foram mencionados, entre outros: conhecer melhor o mundo cultural dos alunos; perceber que os alunos trazem experiências que são significativas e importantes; relatos de histórias de vida; observar a cultura da escola, buscando elementos que possam quebrar a homogeneidade; refletir sobre os conhecimentos que se pretende construir e problematizar as formas de construção desses conhecimentos na escola; ouvir e prestar a atenção aos diferentes atores presentes na escola, se aproximar e sentir o outro; descobrir no corpo docente quem são as pessoas mais sensíveis ao tema; estabelecer parcerias.

Foi salientado com força que a formação continuada é o principal elemento potencializador, “porque não tem como a gente trabalhar com essa questão da interculturalidade se você não tem espaços de formação continuada onde os professores possam conversar sobre isso, essa é a grande dificuldade” (Júlia).

Consideramos que o principal limite da experiência desenvolvida, além dos decorrentes de sua inserção num programa de pós-graduação e suas normas, foi o fato de as participantes estarem vinculadas a diversas escolas. Se essa realidade, por um lado, favoreceu uma riqueza de experiências e dados, por outro, não contribuiu para um trabalho coletivo nas escolas, o que consideramos que teria potencializado 
muito mais o trabalho desenvolvido. É nesse sentido que gostaríamos de caminhar.

Na avaliação do curso, as professoras participantes valorizaram muito positivamente o processo vivido e ressaltaram o fato de ter sido um curso diferente, propiciando que a prática de suas próprias salas de aula pudesse ser incorporada na sala de aula universitária. No entanto, elas afirmaram também que esse tinha sido um primeiro passo e que seria necessário dar continuidade ao vivido para que a incorporação da educação intercultural em sua experiência docente fosse consolidada.

\section{CONSIDERAÇÕES FINAIS}

Certamente a sensibilidade para as questões relacionadas às diferenças culturais vem aumentando na sociedade e nos contextos educativos. No entanto, são muitos os desafios para se desenvolver a educação intercultural nas nossas escolas, especialmente se assumimos a perspectiva da interculturalidade crítica e quisermos superar uma maneira estereotipada e superficial de tratar o tema, reduzido à incorporação de expressões culturais em momentos específicos, em geral, em comemorações de datas previstas no calendário escolar.

Consideramos também que as políticas públicas atualmente vigentes na área de educação parecem ter uma visão dicotômica dos processos educativos. Por um lado, a lógica da homogeneização impera, apoiada particularmente na multiplicação de instrumentos avaliativos com base em testes padronizados sobre determinadas áreas curriculares, que estimulam a homogeneização do sistema. Por outro, várias são as políticas e normativas orientadas ao reconhecimento das diferenças, especialmente promovidas pela Secretaria de Educação Continuada, Alfabetização, Diversidade e Inclusão - Secadi -, do Ministério da Educação. Mas essas não têm a mesma força, nem os apoios implementadores das primeiras. E essas duas perspectivas não parecem dialogar, o que consideramos fundamental. Não se trata de negar elementos comuns que perpassem o sistema educacional, mas sim pensar estratégias participativas de sua construção, assumindo-se também como princípio comum o reconhecimento e valorização das diferenças culturais.

Por meio da experiência desenvolvida foi possível evidenciar a pressão homogeneizadora que os educadores e educadoras sofrem e os poucos espaços disponíveis para se trabalhar outros temas não diretamente ligados aos testes locais ou nacionais considerados referência central da qualidade da educação.

No entanto, a formação continuada de educadores, tendo como lócus as escolas, se revelou como o ponto fundamental para um trabalho sistemático de incorporação da educação intercultural nas nossas escolas. Se não formos capazes de trabalhar essa perspectiva não avançaremos na 


\section{REFERÊNCIAS}

CANDAU, Vera Maria. Mudanças culturais e redefinição do escolar: tensões e buscas. Contemporaneidade e educação, Rio de Janeiro, Ano III, p. 14-26, 1998.

CANDAU, Vera Maria. Cotidiano escolar e cultura(s): encontros e desencontros. In: CANDAU, Vera Maria (Org.). Reinventar a escola. Rio de Janeiro: Vozes, 2000. p. 61-78.

CANDAU, Vera Maria (Org.). Sociedade, educação e cultura(s): questões e propostas. Rio de Janeiro: Vozes, 2002.

CANDAU, Vera Maria. Educação intercultural no contexto brasileiro: questões e desafios. In: SEMINÁRIO INTERNACIONAL DE EDUCAÇÃO INTERCULTURAL, GÊNERO E MOVIMENTOS SOCIAIS, 2., 2003, Florianópolis. Anais... Florianópolis: Universidade Federal de Santa Catarina, 2003.

CANDAU, Vera Maria. Universidade e diversidade cultural: alguns desafios a partir da experiência da PUC-Rio. In: PAIVA, Ângela R. (Org.). Ação afirmativa na universidade: reflexão sobre experiências concretas Brasil-Estados Unidos. Rio de Janeiro: Editora PUC-Rio/Desiderata, 2004. p. 87-108.

CANDAU, Vera Maria (Org.). Cultura(s) e educação: entre o crítico e o pós-crítico. Rio de Janeiro: DP\&A, 2005.

CANDAU, Vera Maria (Org.). Educação intercultural e cotidiano escolar. Rio de Janeiro: 7 Letras, 2006.

CANDAU, Vera Maria. Direitos humanos, educação e interculturalidade: as tensões entre igualdade e diferença. Revista Brasileira de Educação, Rio de Janeiro, v. 13, n. 37, p. 45-56, 2008a.

CANDAU, Vera Maria (Coord.). Multiculturalismo, direitos humanos e educação: a tensão entre igualdade e diferença: relatório de pesquisa. Rio de Janeiro: CNPq/Departamento de Educação, PUC-Rio, 2008b.

CANDAU, Vera Maria (Org.). Educação intercultural na América Latina: entre concepções, tensões e propostas. Rio de Janeiro: 7 Letras, 2009.

CANDAU, Vera Maria (Org.). Reinventar a escola. 7. ed. Petrópolis: Vozes, 2010.

CANDAU, Vera Maria (Org.). Diferenças culturais e educação: construindo caminhos. Rio de Janeiro: 7 Letras, 2011.

CANDAU, Vera Maria. Diferenças culturais, interculturalidade e educação em direitos humanos. Educação \& Sociedade, v. 33, n. 118, p. 235-250, 2012.

CANDAU, Vera Maria. Concepção de educação intercultural. Rio de Janeiro: Editora PUC-Rio, 2014. (Documento de trabalho).

DUBET, François. Mutações cruzadas: a cidadania e a escola. Revista Brasileira de Educação, Rio de Janeiro, v 16, n. 47, p. 289-305, maio/ago. 2011.

GATTI, Bernardete A. Pesquisa em ação: produção de conhecimentos e produção de sentidos como desafio. In: SEMINÁRIO PESQUISA E PÓS-GRADUAÇÃO. São Leopoldo-RS, 2008. Anais... São Leopoldo: Unisinos, 2008.

LERNER, Delia. Enseñar en la diversidad. In: CONFERENCIA DICTADA EN LAS PRIMERAS JORNADAS DE EDUCACIÓN INTERCULTURAL DE LA PROVINCIA DE BUENOS AIRES: GÉNERO, GENERACIONES Y ETNICIDADES EN LOS MAPAS ESCOLARES CONTEMPORÁNEOS. La Plata, Dirección de Modalidad de Educación Intercultural, 28 de junio de 2007. Lectura y Vida: Revista Latinoamericana de Lectura, Buenos Aires, v. 28, n. 4, dez. 2007.

RAVITCH, Diane. Vida e morte do grande sistema escolar americano: como os testes padronizados e o modelo de mercado ameaçam a educação. Porto Alegre: Sulina, 2011.

SANTOS. Boaventura Sousa. Modernidade, identidade e a cultura de fronteira. Tempo Social: Revista de Sociologia, São Paulo, v. 5, n. 1-2, p. 31-52, 1993. 
STOER, Stephen; CORTESÃO, Luisa. "Levantando a pedra”: da pedagogia inter/multicultural às políticas educativas numa época de transnacionalização. Porto: Afrontamento, 1999.

THIOLLENT, Michel. Metodologia da pesquisa-ação. São Paulo: Cortez, 2011.

WALSH, Catherine. Interculturalidad y (de)colonialidad: perspectivas críticas y políticas. In: CONGRESO DA ASSOCIATION POUR LA RECHERCHE INTERCULTURELLE, 12., 2009, Florianópolis. Anais... Florianópolis: UFSC, 2009.

\section{VERA MARIA FERRÃO CANDAU}

Professora emérita do Departamento de Educação da Pontifícia Universidade Católica do Rio de Janeiro - PUC-Rio -, Rio de Janeiro, Rio de Janeiro, Brasil vmfc@puc-rio.br 